EPiC Series in Engineering
Volume 3, 2018, Pages 2096-2104
HIC 2018. 13th International
Conference on Hydroinformatics

\title{
Probability of null water demand characterization
}

\author{
Tricarico C. ${ }^{1}$, Gargano R. ${ }^{1}$, Santopietro S. ${ }^{1}$, Granata F. ${ }^{1}$ \\ ${ }^{1}$ Università degli Studi di Cassino e del Lazio Meridionale, via Di Biasio 43 - 03043 Cassino, \\ Italy \\ c.tricarico@unicas.it, gargano@unicas.it, \\ s.santopietro@unicas.it, f.granata@unicas.it
}

\begin{abstract}
Water demand characterization when this assumes minimum values, if not null ones, is of fundamental importance for the hydraulic network management analysis. In fact, when this water demand condition occurs - usually during the night time - maximum pressures are on network pipes and at the same time tank levels increase and treatment plants are supplied with the minimum flow. The study of the null water demand are furthermore of great interest for leakages analysis in water complex systems. In this paper a study of the probability of null residential demand is provided by referring to different case studies in which the number of users ranges between 500-1250. In order to be able of implementing this study in a water distribution modeling, relationships for the daily null water demand characterization in function of the users supplied and the interval time discretization are also proposed.
\end{abstract}

\section{Introduction}

Water demand modeling is a critical aspect in Water Distribution Systems (WDS) hydraulic and quality simulations. During the day and especially at night time, however, the water demanded by the users assumes the minimum value - if not a null ones. The characterization of the null water demand probability is nowadays a necessary prerequisite to obtain reliable analysis for WDS management [1].

Many works in scientific literature have tackled this problem with a wide spectrum of approaches. Several stochastic models describing the water demand for few end users were proposed (e.g. [2], [3], [4], [5]). These approaches model the residential water demand as it happens at the hydro-sanitary devices of a dwelling. Therefore, the resulting flows are composed by the overlapping of several rectangular pulses, which are generated by tuning on the hydro-sanitary devices.

On the other hand, when the number of the users increases (more than 500), the trend of the water demand during the day becomes smooth and the single pulses are no longer distinguishable (e.g. [6], 
[7]). In these conditions the water demand can be represented by means of a unique random variable which is continuous and positive.

This work is focused on the null water demand by referring to stochastic water demand models for a number of users ranging in between 500 - 1250, even if results obtained could lead to wider considerations. Modeling of the null water demand, which presents a higher probability during the night hours, have a significant role in one of the most onerous condition for a WDS in terms of pressures. The study of the conditions in which the water demand is null - or more generally when it assumes minimum values - are of significance in the leakages estimation analysis and for the estimation of the tank levels increase. Furthermore the choice of the time step discretization plays an important rule for the study of the null water demand probability. In the technical literature there are several contribution on the incidence of the interval time of discretization [8], [9], [10],[11] while few are the contribution on the effect of the temporal step on the probability of $\mathrm{Q}=0$ [12].

On these basis a more detailed description of this probability is thus required for a better representation of the water demand and its characterization for analysis in the hours of minimum consumption. Moving from these considerations, relationship for its estimation are provided in function of the users served and analysis of the temporal resolution has been applied in order to analyze the effects of the interval time on the null demanded flow.

\section{Methodology}

Water demand has been considered dimensionless by means of the demand coefficient CD:

$$
C_{D}(t)=\frac{Q(t)}{\mu_{Q}}
$$

where $\mu_{Q}$ is the daily mean water demand, and $Q(t)$ the value of water demand at the time $t$.

As already reported in [7] if the total probability theorem is applied for the random variable $C_{D}$, the resulting CDF is:

$$
F\left[C_{D}\right]=\operatorname{Pr}\left[C_{D}=0\right] \cdot \operatorname{Pr}\left[C_{D}<C_{D} \mid C_{D}=0\right]+\operatorname{Pr}\left[C_{D}>0\right] \cdot \operatorname{Pr}\left[C_{D}<C_{D} \mid C_{D}>0\right]
$$

If with $\mathrm{F}_{\mathrm{o}}$ it is indicated the occurrence probability that the water demand is null $\left(\mathrm{F}_{\mathrm{o}}=\operatorname{Pr}\left[C_{D}=0\right]\right)$, and with $\mathrm{F}^{*}$ the $\mathrm{CDF}$ of the flow demand when it is not null $\left(\mathrm{F}^{*}=\operatorname{Pr}\left[C_{D}<c_{D} \mid C_{D}>0\right]\right)$, Eq. (2) can be rewritten as:

$$
\mathrm{F}\left[\mathrm{C}_{\mathrm{D}}(\mathrm{t})\right]=\mathrm{F}_{\mathrm{o}}(\mathrm{t})+\left(1-\mathrm{F}_{\mathrm{o}}(\mathrm{t})\right) \mathrm{F}^{*}(\mathrm{t})
$$

where with $t$ has been indicated the dependence of the $\mathrm{F}_{\mathrm{o}}$ and $\mathrm{F}^{*}$ on the time. The $\mathrm{F}_{\mathrm{o}}(\mathrm{t})$ probability is strictly connected to the users' habits which are responsible of the daily demand pattern behaviour and thus of the $C_{D}(t)=0$. Furthermore, as reported in [7], [12] the probability of null water demand value depends significantly on the interval time $\Delta \mathrm{t}$ with which the day has been discretized by decreasing exponentially by increasing it and on the number of users supplied.

In practical applications, the choice of the temporal resolution is an important parameter that decision makers have to set. A more refined time resolution allows to perform more precise analysis, but implies in general a higher computational complexity. On the other hand, a coarser time resolution 
allows to have a more manageable problem complexity but a more approximate representation. As it could be expected, time resolution influences strongly the probability of null water demand, in particular it tends to decrease with greater averaging time intervals.

In order to accomplish the above consideration, three different case studies supplying users ranging in between 500 and 1220, characterized by a different behavior in the water consumption, have been analyzed, taking into consideration also the incidence of the $\Delta \mathrm{t}$.

The case studies examined are the WDSs of Piedimonte San Germano - PSG (South of Italy) which demand data have been compared with those of other residential users. In particular, the networks of Castelfranco Emilia - CE (North of Italy) [3] and Franeker - FR (Netherland) [13] have been considered.

PSG network - realized by Laboratorio di Ingegneria delle Acque of the Università di Cassino e del Lazio Meridionale - has meters located strategically in the network which can allow measurement of the water demand for several Demand Monitoring Area (DMA) with a different number of users. In particular for this analysis have been considered three different DMAs with a number of users equal to 777, 981 and 1220 respectively. Monitored users in the CE network are 596, while for FR are 1150. Main characteristics of the monitoring systems are reported in Table 1.

\begin{tabular}{r|ccc} 
& PSG (I) & FR (NL) & CE (I) \\
\hline \hline$N_{u s}$ & $777-1220$ & 1150 & 596 \\
\hline $\begin{array}{r}\text { Monitored period } \\
\text { Type of counter }\end{array}$ & $\begin{array}{c}24 \text { Nov 08-13 } \\
\text { Apr.2009 }\end{array}$ & $\begin{array}{c}\text { 23 Jan. - 31 Mar. } \\
2006\end{array}$ & $\begin{array}{c}\text { J Jan. - 20 Mar. } \\
\text { sampling }\end{array}$ \\
\hline $\begin{array}{r}\text { Frequency of } \\
\text { for the statistics }\end{array}$ & $1 \mathrm{~Hz}$ & Flow meter & Volumetric meter \\
\hline $\begin{array}{r}\text { Number of used days } \\
\text { for the }\end{array}$ & 85 & $1 / 60 \mathrm{~Hz}$ & $1 / 60 \mathrm{~Hz}$ \\
\hline
\end{tabular}

Table 1 - Main characteristics of the monitoring systems

On the basis of the collected data, analysis of the probability of null water demand has been undertaken by considering the $\Delta \mathrm{t}=1$ minute, 5 minutes and 10 minutes. Greater time intervals have not been considered because for the number of aggregated users considered (500-1250) the $F_{o}$ value is almost null.

Because a different consumption was observed between weekends and weekdays, only the latter were analyzed. Patterns of the water demanded by the three monitoring systems are reported in Figure 1 in reference to $\Delta t=1$ minute. As of evidence, the behaviour in the use of water is different for the case studies examined: PSG presents three decreasing peaks during the day, where the first peak demand in the monitoring is considerably higher; FR pattern presents two daily peaks characterized by almost the same entity, while $\mathrm{CE}$ is a middle ground trend with a peak in the evening greater than that in the morning. 

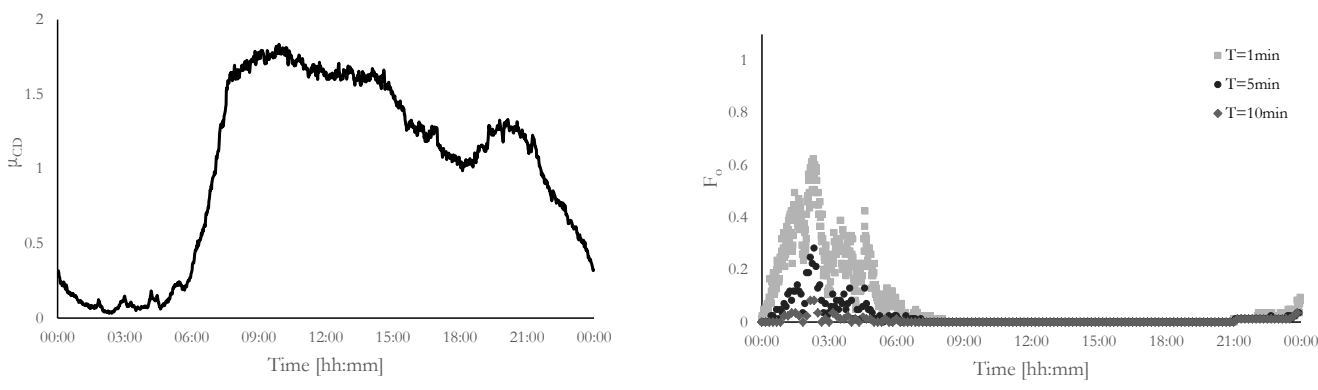

PSG $-N_{u s}=1220$
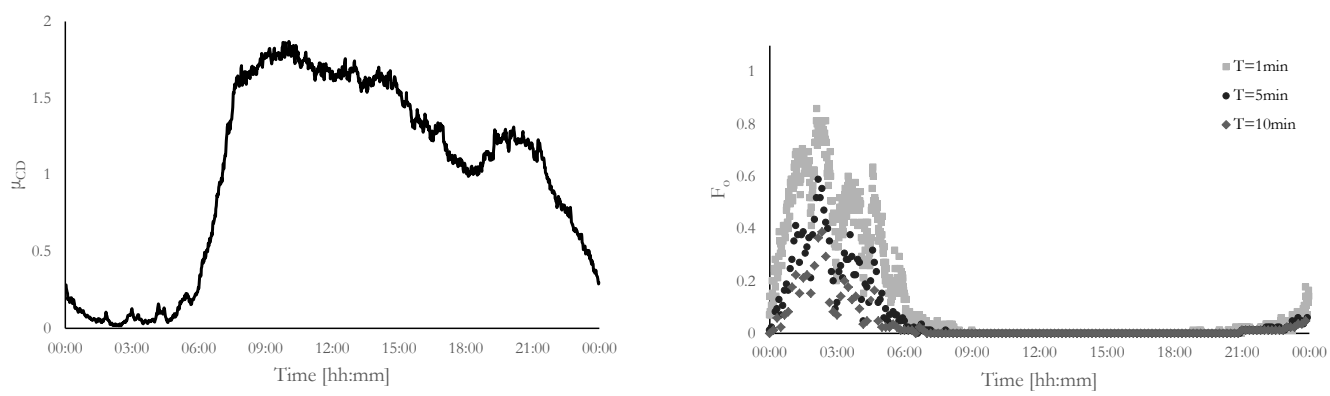

PSG $-N_{u s}=981$
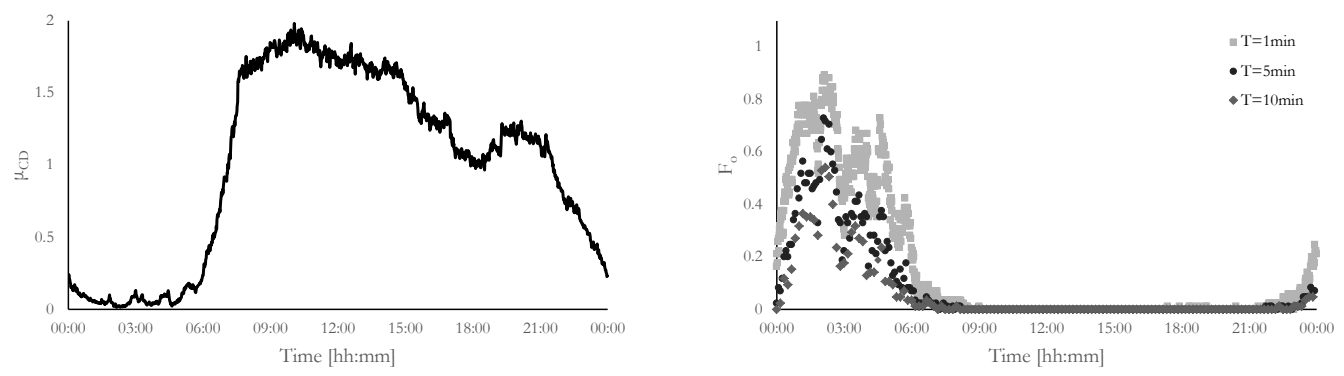

PSG $-N_{u s}=777$
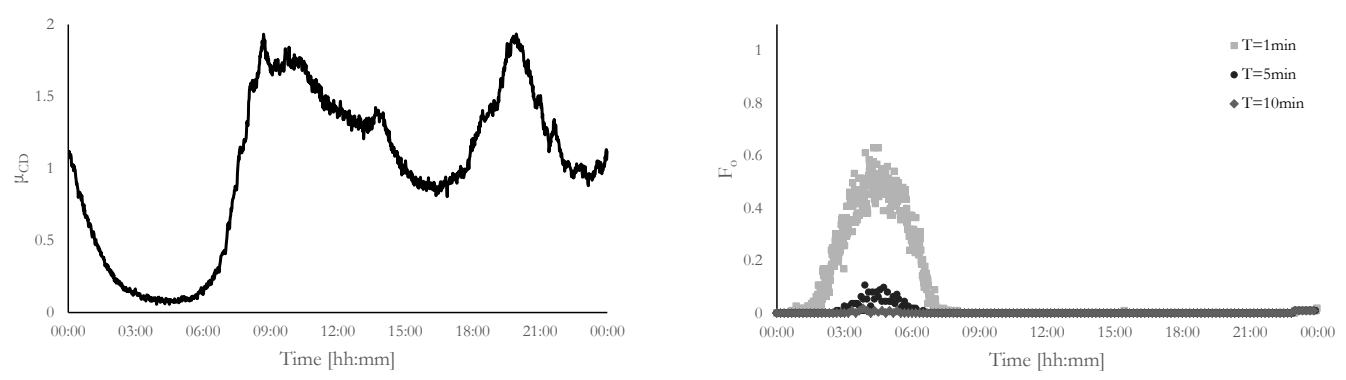

FR $-N_{u s}=1150$ 

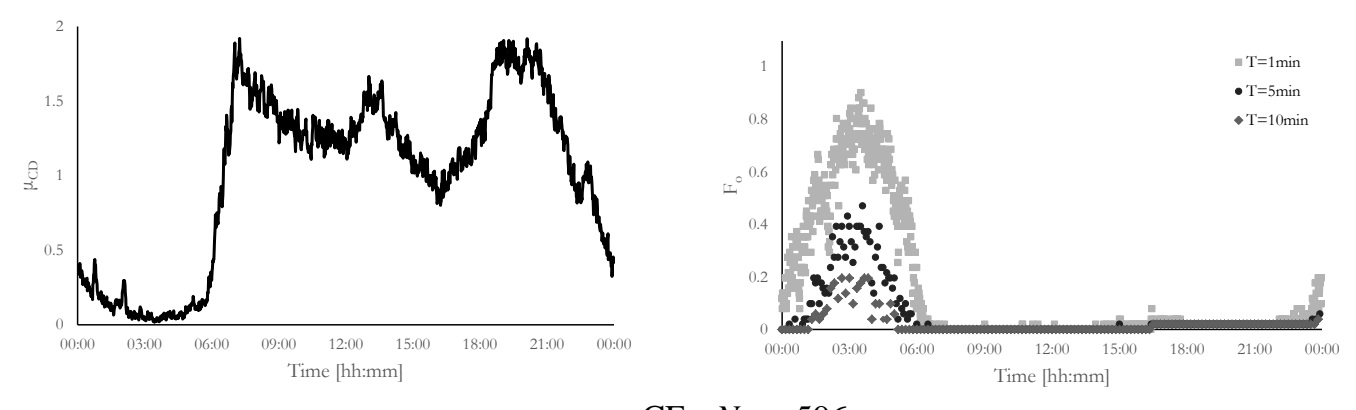

$\mathrm{CE}-N_{u s}=596$

Figure 1 - Daily trend of the residential water demand for the three analysed case studies compared with the daily trend of $F_{o}$ for different time aggregation intervals

The daily behaviour of the $\mathrm{F}_{\mathrm{o}}(\mathrm{t})$ for the three case studies is also reported in Figure 1 by varying the values of the aggregation interval $\Delta \mathrm{t}$. As it was expected, the probability of null water request assumes significant values during the hours of minus consumption (night time) while it is substantially null during the rest of the day, by verifying the strictly connection of this probability with the users' habits.

$F_{o}$ increases when the number of users decreases and decreases when the interval time of discretization increases. By increasing the interval time, the probability that $C_{D}=0$ reduces till to zero for $\Delta t>10$ minutes. This is also more evident when the number of users increase. On the other side, for a minus number of users respect to that investigated, $F_{o}(t)$ could present non null values also in other times of the day.

The null water demand probability assumes maximum values during the night hours by reaching values close to the unit at the decreasing of the number of users. Gargano et al. [7] proposed a relation for the estimation of the maximum probability of the null water demand. Herein, the developed analyses by considering the effect of the time scale have been shown that $\mathrm{F}_{\mathrm{o}}{ }^{\max }$ decreases with the increase of the time step of discretization and increases by reducing the number of users. This trend is described by means of the (4) which recalls the similar relationship proposed in [7] but, as mentioned before, valid only for $\Delta t=1$ minute.

$$
\mathrm{F}_{\mathrm{o}}^{\max }=1-(0.25+0.15 \ln \Delta \mathrm{t})\left(\frac{\mathrm{N}_{\mathrm{us}}}{1000}\right)^{2.5}
$$

Where $N_{u s}$ is the number of served inhabitants. Therefore, Eq (4) estimates the probability of $\mathrm{F}_{\mathrm{o}}{ }^{\max }$ in relation to $N_{u s}$ and the discretization time. As the plots reported in Figure 1 the $\mathrm{F}_{\mathrm{o}}{ }^{\max }$ tends rapidly to 1 for a small number of users and for the same number of users it is reducing by increasing the $\Delta t$.

The CE data does not fit Eq (4) for a time interval greater than 1 minute, as reported in Figure 2, because the flow measurements were made by volumetric probes at difference of FR and PSG were electromagnetic flow measures were installed. 

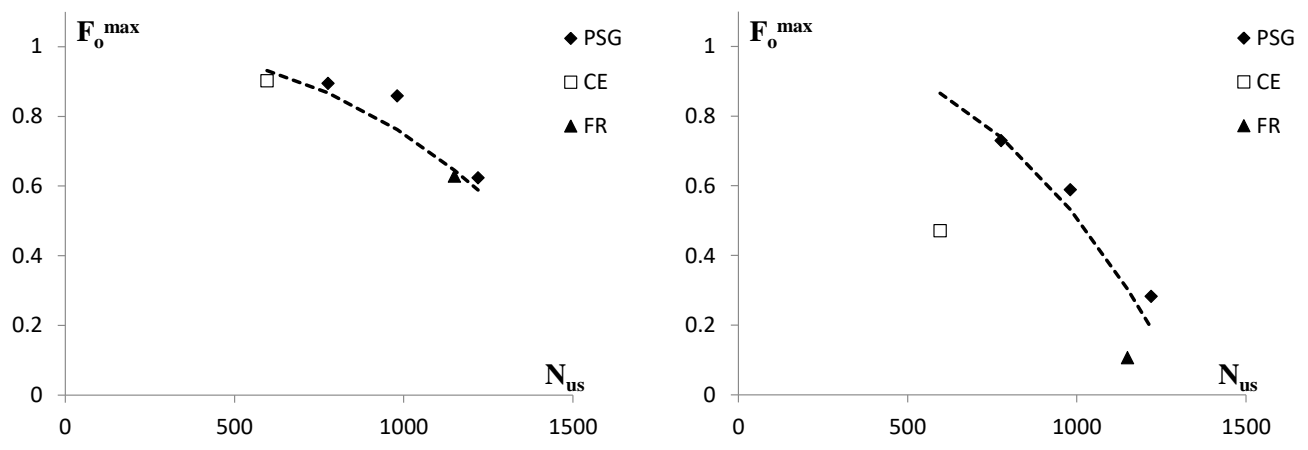

$\Delta \mathrm{t}=1$ minute

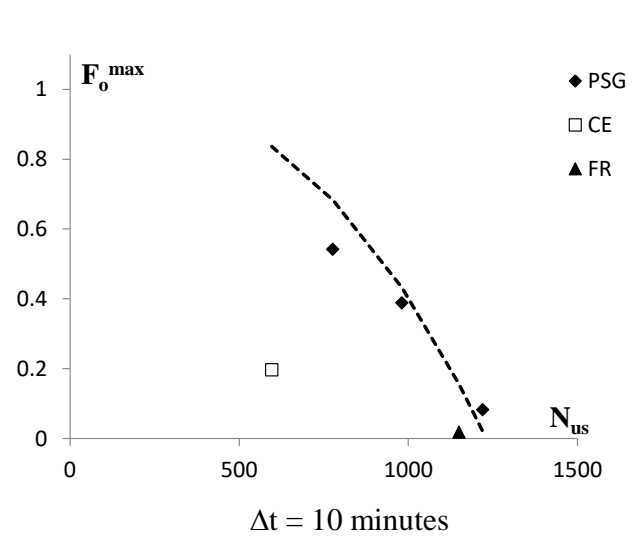

Figure 2 - Equation (4) (----) for the estimation of $\mathrm{F}_{o}^{\max }$ versus $\mathrm{N}_{\mathrm{us}}$ and observed data for different time aggregation intervals

Experimental data show also a trend, proposed in Eq.(5), of the probability of null water demand during the day. This depends on the number of the served users and on the mean demand coefficient in function of the several time aggregations:

$$
\mathrm{F}_{\mathrm{o}}=\exp \left(-5 \Delta \mathrm{t} \frac{\mathrm{N}_{\mathrm{us}}}{1000} \mu_{\mathrm{C}_{\mathrm{D}}}\right)
$$

The plots reported in Figure 3 show the effectiveness of Eq.(5) for different $\Delta t$ and for the investigated users. As expected, the probability value promptly decreases towards zero already for demand coefficient values close to the daily mean value.

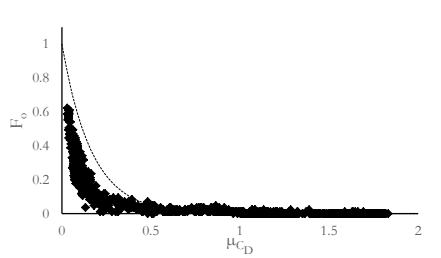

PSG (1220 users) - $\Delta \mathrm{t}=1 \mathrm{~min}$

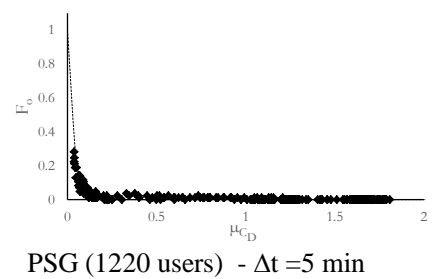

PSG (1220 users) - $\Delta \mathrm{t}=5 \mathrm{~min}$

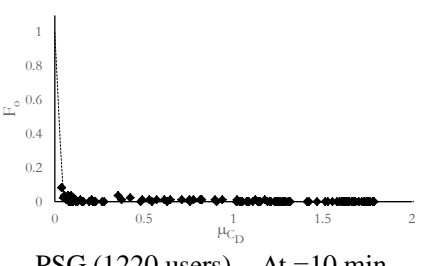

PSG (1220 users) $-\Delta t=10 \mathrm{~min}$ 


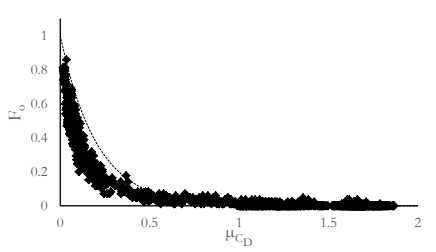

PSG (981 users) $-\Delta \mathrm{t}=1 \mathrm{~min}$

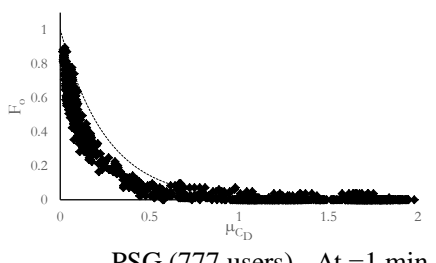

PSG (777 users) - $\Delta \mathrm{t}=1 \mathrm{~min}$

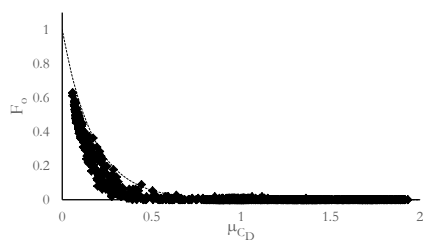

$\mathrm{FR}-\Delta \mathrm{t}=1 \mathrm{~min}$

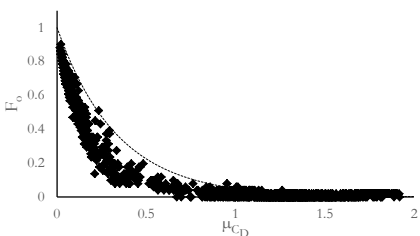

$\mathrm{CE}-\Delta \mathrm{t}=1 \mathrm{~min}$

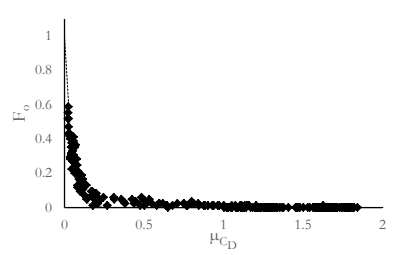

PSG (981 users) $-\Delta \mathrm{t}=5 \mathrm{~min}$

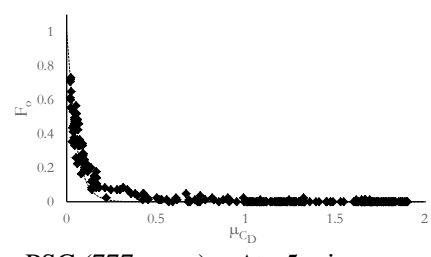

PSG (777 users) $-\Delta \mathrm{t}=5 \mathrm{~min}$

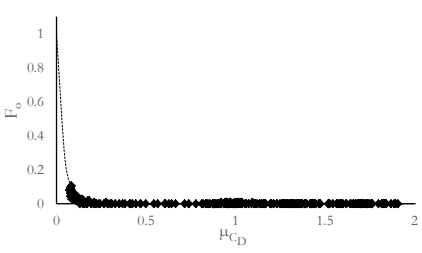

$\mathrm{FR}-\Delta \mathrm{t}=5 \mathrm{~min}$

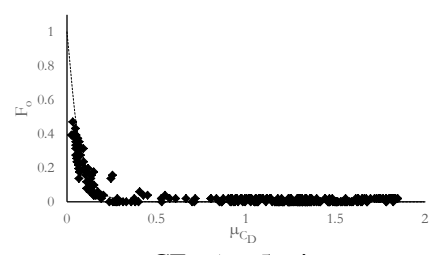

$\mathrm{CE}-\Delta \mathrm{t}=5 \mathrm{~min}$

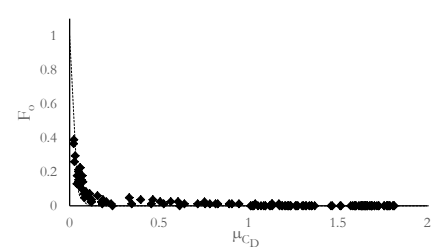

PSG (981 users) $-\Delta \mathrm{t}=10 \mathrm{~min}$

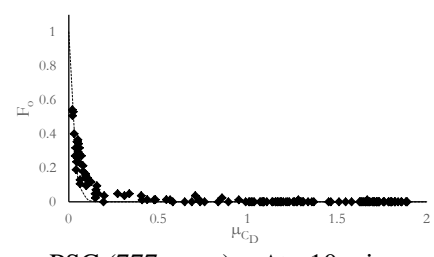

PSG (777 users) $-\Delta t=10 \mathrm{~min}$

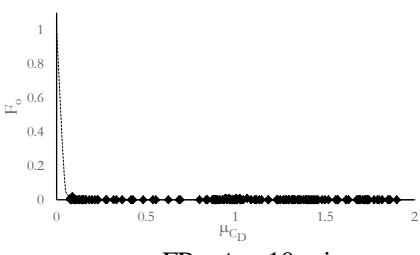

$\mathrm{FR}-\Delta \mathrm{t}=10 \mathrm{~min}$

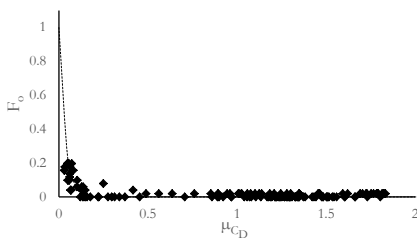

$\mathrm{CE}-\Delta \mathrm{t}=10 \mathrm{~min}$

Figure3 - Eq. (5) (---) and observed data of $\mathrm{F}_{\mathrm{o}}$ versus $\mu_{C_{D}}$ by varying the $\Delta \mathrm{t}$

Equation (5) for each of the interval time considered is plotted in Figure 5 for the different number of users examined.
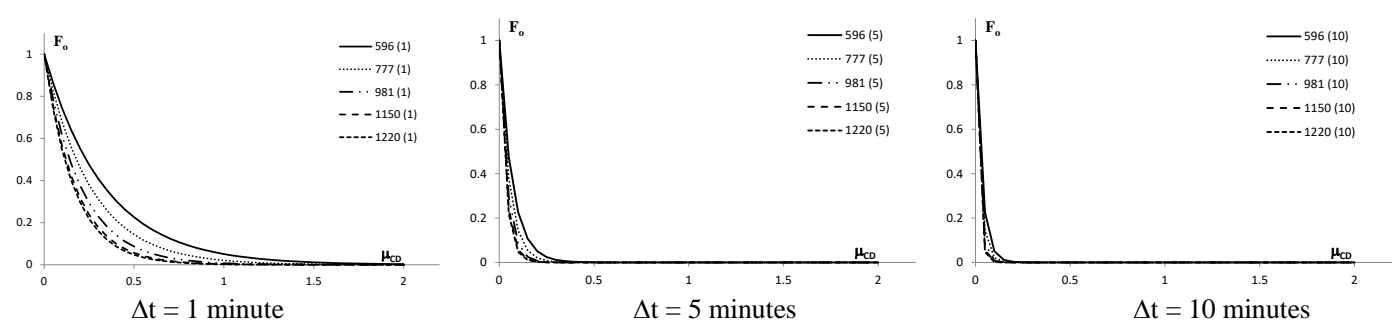

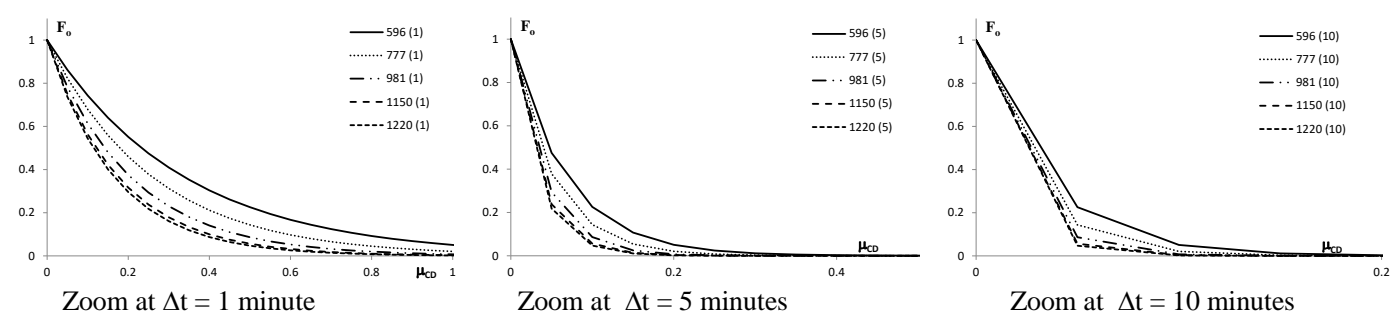

Figure 4 - Eq. (5) (---) by varying the $\Delta t$ and the number of users

The condition of $F_{o}=1$ represents a theoretical limit, because the event of the null water request cannot be a certain event, also during the night time. Therefore the Eq.(5) becomes unfounded when the value of $\mu_{\mathrm{CD}}(\mathrm{t})$ leads to a probability of null water demand higher than Eq.(4). Therefore, the domain of Eq.(5) is limited inferiorly by the a threshold value $\mu_{\mathrm{Cm}}$.

If it is assumed that $\mu_{\mathrm{Cm}}$ occurs at the same time of the maximum value $\mathrm{F}_{\mathrm{o}}{ }^{\max }$ - condition however close to the reality- then $\mu_{\mathrm{Cm}}$ value for a number of users ranging among 500-1250, can be obtained by equalling Eq.s (4) and (5):

$$
\mu_{\mathrm{C}_{\mathrm{m}}}=-\frac{200}{\Delta \mathrm{t} \cdot \mathrm{N}_{\mathrm{us}}} \ln \left[1-(0,25+0.15 \ln \Delta \mathrm{t})\left(\frac{\mathrm{N}_{\mathrm{us}}}{1000}\right)^{2,5}\right]
$$

Equation (6) give the minimum threshold value for which the $\mathrm{F}_{\mathrm{o}}(\mathrm{t})$ could be considered admissible. It varies in function of the number of users supplied and the time interval of discretization. Hence, when $\mu_{\mathrm{CD}}$ is minor than the value of the Eq.(6), $\mathrm{F}_{\mathrm{o}}(\mathrm{t})$ should be assumed equal to the maximum value obtained by means of Eq.(4).

In such a way, the daily trend of the $\mathrm{F}_{\mathrm{o}}(\mathrm{t})$ probability could be estimated by knowing the $\mu_{\mathrm{CD}}$ pattern jointly with the application of Eq.s (4)-(6).

\section{Conclusions}

The probability of null water demand has been studied for three different case studies in which the users number ranged between 500 and 1250. By analyzing the different habits of the users in the minimum water consumption, relationships useful for the estimation of the daily trend of the probability of null water demand in function of the users number have been proposed. The incidence of the different interval time used in the data discretization has been further analyzed. Time resolution influences strongly the probability of null water demand, in particular it tends to decrease with greater averaging time intervals.

The goodness of the results have shown the possibility to implement the proposed relationships in water distribution modeling in order to characterize the probability of null request.

\section{References}

[1] C. Tricarico, S. M. Morley, R. Gargano, Z. Kapelan, G. de Marinis, D. Savic, F. Granata, "Integrated optimal cost and pressure management for water distribution systems", Procedia Engineering, vol.70, p.1659-1668, ISBN: 9780000000002, ISSN: 1877-7058, 2014 
[2] S. Buchberger and L. Wu, "Model for Instantaneous Residential Water Demands," J. Hydraul. Eng., vol. 121, no. 3, pp. 232-246, Mar. 1995.

[3] S. Alvisi, M. Franchini, and A. Marinelli, "A stochastic model for representing drinking water demand at residential level,” Water Resour. Manag., vol. 17, no. 3, pp. 197-222, 2003.

[4] E. Blokker, J. Vreeburg, and J. van Dijk, "Simulating Residential Water Demand with a Stochastic End-Use Model," J. Water Resour. Plan. Manag., vol. 136, no. 1, pp. 19-26, Mar. 2010.

[5] R. Gargano, F. Di Palma, G. de Marinis, F. Granata, and R. Greco, "A stochastic approach for the water demand of residential end users," Urban Water J., vol. 13, no. 6, pp. 569-582, Aug. 2016.

[6] B. Janković-Nišić, Č. Maksimović, D. Butler, and N. J. Graham, "Use of flow meters for managing water supply networks," J. Water Resour. Plan. Manag., vol. 130, no. 2, pp. 171-179, 2004.

[7] R. Gargano, C. Tricarico, G. del Giudice, and F. Granata, "A stochastic model for daily residential water demand," Water Sci. Technol. Water Supply, vol. 16, no. 6, pp. 1753-1767, Dec. 2016.

[8] Alvisi, S., Ansaloni, N. and Franchini, M. "Generation of Synthetic Water Demand Time Series at Different Temporal and Spatial Aggregation Levels" Urban Water Journal, Volume Vol.11(4), 297-310 - 2014.

[9] Moughton L. J., Buchberger S. G., Boccelli D. L., Filion Y. R., Karney B. W. "Effect of time step and data aggregation on cross correlation of residential demands". Proceeding of 8th Annual International Symposium on Water Distribution Systems Analysis, Cincinnati, OH (USA), p.42, 2007.

[10] Vertommen I., Magini R., Cunha M.C. "Scaling Water Consumption Statistics", Journal of Water Resources Planning and Management, ASCE, Vol.141(5), 04014072, 2005.

[11] Gargano R., Tricarico C., Granata F., Santopietro S., de Marinis G., "Probabilistic models for the Peak Residential Water Demand", WATER Volume 9, Issue 6 DOI: 10.3390/w9060417, 2017

[12] S. Buchberger and G. Nadimpalli, "Leak Estimation in Water Distribution Systems by Statistical Analysis of Flow Readings", J. Water Resour. Plan. Manag., vol. 130, no. 4, pp. 321-329, 2004.

[13] E. Blokker, J. Vreeburg, and A. Vogelaar, "Combining the Probabilistic Demand Model SIMDEUM with a network model" In: Proceedings of the 8th Annual International Symposium on Water Distribution Systems Analysis. Cincinnati, OH, USA, 2006 